\title{
Tropospheric aerosol profile information from high-resolution oxygen A-band measurements from space
}

\author{
A. Geddes and H. Bösch \\ Earth Observation Science Group, Dept. of Physics and Astronomy, University of Leicester, Leicester, UK \\ Correspondence to: A. Geddes (ag204@le.ac.uk)
}

Received: 3 June 2014 - Published in Atmos. Meas. Tech. Discuss.: 17 June 2014

Revised: 22 December 2014 - Accepted: 26 January 2015 - Published: 20 February 2015

\begin{abstract}
Aerosols are an important factor in the Earth climatic system and they play a key role in air quality and public health. Observations of the oxygen A-band at $760 \mathrm{~nm}$ can provide information on the vertical distribution of aerosols from passive satellite sensors that can be of great interest for operational monitoring applications with high spatial coverage if the aerosol information is obtained with sufficient precision, accuracy and vertical resolution. To address this issue, retrieval simulations of the aerosol vertical profile retrieval from $\mathrm{O}_{2}$ A-band observations by GOSAT, the upcoming Orbiting Carbon Observatory-2 (OCO-2) and Sentinel 5-P missions, and the proposed CarbonSat mission have been carried out. Precise retrievals of aerosol optical depth (AOD) within the boundary layer were found to favour lowresolution, high signal-to-noise instruments such as Sentinel$5 \mathrm{P}$, whereas higher-resolution instruments such as OCO-2 showed greater performance at higher altitudes and in information content above the boundary layer. Retrieval of the AOD in the $0-2 \mathrm{~km}$ range with precision appears difficult from all studied instruments and the retrieval errors typically exceed a value of 0.05 for AODs up to 0.3. Constraining the surface albedo is a promising and effective way of improving the retrieval of aerosol, but the accuracy of the required prior knowledge is very high. Due to the limited information content of the aerosol profile retrieval, the use of a parameterised aerosol distribution is assessed, and we show that the AOD and height of an aerosol layer can be retrieved well if the aerosol layer is uplifted to the free troposphere; however, errors are often large for aerosol layers in the boundary layer. Additional errors are introduced by incorrect assumptions on surface pressure and aerosol mixture, which can both bias retrieved AOD and height by up to $45 \%$. In addition, assumptions of the boundary layer temperature are found to yield an
\end{abstract}

additional error of up to $8 \%$. We conclude that the aerosol profile retrievals from $\mathrm{O}_{2}$ A-band using existing or upcoming satellite sensors will only provide limited information on aerosols in the boundary layer but such observations can be of great value for observing and mapping aerosol plumes in the free troposphere.

\section{Introduction}

Aerosols play a key role for the Earth's climate, atmospheric composition and air quality. They also impact human life since they contain a variety of hazardous organic and inorganic substances and reduce visibility (WHO, 2007).

Aerosols directly impact the radiation budget of the Earth by scattering and absorbing solar radiation and by interacting with clouds. The combined effects contribute $-0.9(-1.5$ to $-0.4) \mathrm{W} \mathrm{m}^{-2}$ to the likely total effective radiative forcing. There is high confidence that they have offset a large fraction of the positive radiative forcing from greenhouse gases (IPCC, 2013), but they also contribute the largest uncertainty to the total radiative forcing estimate.

The impact of aerosol on the radiative forcing depends their vertical distribution. The direct aerosol forcing in the long-wave spectral region, e.g. by mineral dust, depends critically on the vertical profile of aerosols (Dufresne et al., 2002), and the relative location of aerosols and clouds in the vertical is one determining factor for indirect aerosol forcing (e.g. Kaufman et al., 2002). Furthermore, aerosols transported to the free troposphere or stratosphere will be horizontally transported over a large distance, thus impacting large regions, while aerosols confined to the boundary layer are 
removed quickly by rain. Thus the vertical distribution is a deciding factor on the area impacted by aerosols.

Aerosols and their vertical distribution will also directly impact remote sensing observations as aerosols act to vary the path length of photons through their strong scattering properties. Thus observations of atmospheric trace gases or surface parameters such as ocean colour need to be corrected accordingly for these aerosol effects (e.g. Aben et al., 2007; Gordon et al., 1997).

One of the most effective methods of measuring the aerosol vertical structure from space is to use a LIDAR such as the Cloud-Aerosol LIDAR and Infrared Pathfinder Satellite Observations (CALIPSO) (Hunt et al., 2009). LIDARs provide detailed information on the vertical distribution of scatterers as well as information that allows classification of the aerosol type. However, LIDARs suffer from a very small swath; therefore, truly global coverage is not possible with such an instrument. In addition, space-based LIDARs are expensive and large, which are limiting factors for operational monitoring or for combined payloads on satellite platforms.

There are several methods for obtaining vertical information on aerosols or clouds from passive instruments. Solar occultation instruments, e.g. HALOE and SAGE (Russell et al., 1993; Mauldin III et al., 1985), or limb scanners, e.g. MIPAS and OSIRIS (Fischer et al., 2008; Llewellyn et al., 2004), provide some constraint on the aerosol distribution, but this is typically limited to the stratosphere and upper troposphere. Multi-angle observations can also provide some estimate of the height of an aerosol layer from stereo-image techniques if the aerosol layer is sufficiently thick and high (Val Martin et al., 2010) and has been achieved in certain conditions with the Multi-angle Imaging SpectroRadiometer (MISR, Kahn et al., 2007). In addition, the use of polarization and UV observations in constraining aerosol height has been used with some success by instruments such as POLDER and OMI respectively (Dubuisson et al., 2009; Satheesh et al., 2009).

Many important applications related to air quality and climate monitoring, however, require separation of boundarylayer and free-tropospheric aerosol with errors for aerosol optical depth (AOD) of less than 0.02 to 0.05 and a vertical resolution of 1 to $2 \mathrm{~km}$ (WMO, 1994; Siddans et al., 2007).

A promising method for inferring such information on the vertical aerosol distribution from passive instruments is the measurement of the absorption spectrum of molecular oxygen $\left(\mathrm{O}_{2}\right)$. The atmospheric distribution of $\mathrm{O}_{2}$ is well known throughout the atmosphere and thus the absorption lines directly provide information on the optical path length and thus on atmospheric scattering. Traditionally, the $\mathrm{O}_{2}$ A-band in the near-infrared (NIR) at $765 \mathrm{~nm}$ is used for cloud-top pressure (or apparent surface pressure) retrievals (Hanel, 1961; Yamamoto and Wark, 1961; O'Brien and Mitchell, 1992). More recently, the use of $\mathrm{O}_{2}$ A-band measurements for vertical profiling of aerosols has been studied by 1 heidinger 2000 . This profiling capability relies on the large range of optical depths of the absorption lines in the $\mathrm{O}_{2}$ A-band with light from strong absorption lines originating from the upper atmosphere while light for very weak lines will more likely have passed through the atmosphere and be reflected by the surface.

However, as concluded from theoretical studies by 1 heidinger2000, the vertical resolution will be limited and measurements need to be obtained with a spectral resolution of about $0.5 \mathrm{~cm}^{-1}$ and with an accuracy of $2 \%$ or better. Simulations of $\mathrm{O}_{2}$ A-band spectra for the SCIAMACHY instrument by Corradini and Cervino (2006) showed that a maximum of three aerosol layers can be resolved and that aerosols near the surface cannot be retrieved if the surface is bright. They have also pointed out that knowledge of aerosol properties such as single scattering albedo and phase function are of great importance. Retrieving such properties simultaneously along with the profile is difficult but can be enhanced through the combination with a LIDAR, (Heidinger and Stephens, 2000), polarization as in Boesche et al. (2008) or by using multiple angles as discussed by Frankenberg et al. (2012). In the latter, they show that it is possible to retrieve a number of aerosol type parameters along with one aerosol profile centre height and width, showing an increase of $2-4^{\circ}$ of freedom with the addition of two viewing angles compared to the strictly nadir view only.

Hollstein and Fischer (2014) assessed the role of spectral resolution and instrument noise upon the retrieval of aerosol optical depth and height from the $\mathrm{O}_{2}$ A-band using a fast forward operator based upon lookup tables. They conclude that while performance generally increases with improved spectral resolution, particularly above values of $0.1 \mathrm{~nm}$, performance can degrade with increased resolution due to signalto-noise (SNR) requirements. They also discuss the impact of aerosol type with the conclusion that the retrieval is largely immune to such changes, with AOD more strongly affected compared to height.

The $\mathrm{O}_{2}$ A-band is susceptible to chlorophyll fluorescence as discussed by Frankenberg et al. (2011). They state that this effect can introduce significant biases in retrieved aerosol parameters if not taken into consideration. They advocate the use of solar lines to retrieve an intensity offset caused by fluorescence, because otherwise disentangling the effects of aerosols and fluorescence in the $\mathrm{O}_{2}$ A-band would be difficult. Sanders and de Haan (2013) use the fact that the $\mathrm{O}_{2}$ A-band has a number of solar lines, and they retrieve a fluorescence value simultaneously with aerosol with minimal impact upon the accuracy of the aerosol retrieval.

There are a number of satellite instruments that are either currently in orbit, will be launched in the next 12 years or are proposed that will provide measurements of the $\mathrm{O}_{2}$ A-band and will provide valuable information on aerosols. These include the Greenhouse Gas Observing SATellite (GOSAT), which was launched in 2009, Orbiting Carbon Observatory-2 (OCO-2), launched in 2014, the Sentinel 5-Precursor (S-5 P) mission, which will be launched within the next 1-2 years, and the ESA Earth Explorer 8 
candidate mission CarbonSat, a proposed mission for launch around 2020. In this work, we present a synthetic study to assess the capability of these four instruments with largely different instrumental characteristics to retrieve the information on the vertical distribution of aerosols.

Section 2 provides a brief description of the four instruments included in this study, with a focus on their characteristics within the $\mathrm{O}_{2}$ A-band followed by an overview of the simulation and retrieval methods in Sect. 3. In Sect. 4, we present the results obtained from profile retrievals of aerosols for the four instruments for simple (single aerosol layer) and more complex (two aerosol layers) scenarios. Following on from this, we will discuss the effect of introducing additional constraints on the aerosol retrieval by imposing a parameterised shape on the aerosol profile or assuming a priori knowledge on surface albedo. An assessment of systematic errors caused by inaccurate knowledge of aerosol mixtures, surface pressure and temperature on the retrieval of aerosol parameters is given in Sect. 6 and the summary and conclusion are given in Sect. 7.

\section{Instrumentation}

Four space-based instruments are included in this study that provide measurements in the $\mathrm{O}_{2}$ A-band range with a wide variety of spectral resolutions and signal-to-noise characteristics.

GOSAT, launched by the Japanese Space Agency in 2009, is equipped with the TANSO-FTS instrument: a Fourier Transform Spectrometer that provides spectrally resolved radiance measurements in the three shortwaveinfrared (SWIR) bands and a thermal-infrared band (Kuze et al., 2009). GOSAT has a 3-day repeat cycle and TANSOFTS nominally performs a cross-track scanning pattern with a ground pixel $10.5 \mathrm{~km}$ in diameter. Until August 2010, the standard mode consisted of five cross-track points separated by $158 \mathrm{~km}$; this has been changed to three points to reduce pointing errors (Crisp et al., 2012).

The OCO-2 mission launched on 2 July 2014 into the Afternoon constellation (A-train) orbit (Crisp et al., 2004, 2008). The OCO-2 payload consists of a high-resolution grating spectrometer that covers three spectral bands in the SWIR. OCO-2 uses a narrow nadir swath width of $10 \mathrm{~km}$ with ground pixels of area $3 \mathrm{~km}^{2}$ and an orbit with a 16-day repeat cycle.

The S-5 $\mathrm{P}$ mission is a gap-filler and a preparatory programme for the EUMETSAT Polar System Second Generation programme (Ingmann et al., 2012). The planned launch date of S-5 P is in March 2015 and it will fly in formation with the US NPP mission. The S-5 P instrument has four bands in the UV-visible range, two bands in the near-infrared and one SWIR band with moderate spectral resolution. The instrument measures a wide swath of $2600 \mathrm{~km}$ with a spatial resolution of $7 \times 7 \mathrm{~km}^{2}$ and it achieves daily global cover- age. The instrument parameters for S-5 $\mathrm{P}$ used in this study represent a baseline performance given in Buscaglione and Maresi (2011) and changes, particularly in the spectral sampling, could alter the results.

CarbonSat is a satellite mission that has been selected by the European Space Agency (ESA) as one of two candidate missions for ESA's Earth Explorer 8 (EE8) program, with one to be launched around the end of the decade $(\sim 2020)$. CarbonSat is an imaging spectrometer that will cover three spectral bands in the NIR and SWIR with moderate to high spectral resolution. CarbonSat has a high spatial resolution with ground pixels with an area of $2 \times 2 \mathrm{~km}^{2}$ and good spatial coverage via continuous imaging across a $240 \mathrm{~km}$ swath width (goal: $500 \mathrm{~km}$ ) (Bovensmann et al., 1999; Buchwitz et al., 2013).

There is a number of satellite instruments that provide measurements of the $\mathrm{O}_{2}$ A-band such as SCIAMACHY, GOME and GOME-2 that are not included in this study. Their spectral resolution is comparable to that of S-5 P and comparisons are possible with the help of Fig. 3 .

Table 1 gives an overview of the assumed instrument parameters of the four instruments for the $\mathrm{O}_{2}$ A-band range. Simulated example spectra for the four instruments are shown in Fig. 1. GOSAT and OCO-2 acquire $\mathrm{O}_{2}$ A-band spectra with high spectral resolution which allows the separation of individual absorption lines. The structure of the absorption lines is still visible in the CarbonSat spectra, while the resolution of $\mathrm{S}-5 \mathrm{P}$ is too low to observe the line structure of the $\mathrm{O}_{2}$ band. OCO-2 observes roughly half the radiance levels of the other instruments since it measures only one polarization component of the signal. In this study, we have not considered polarization explicitly and we halved the simulated intensity levels for OCO-2 to take into account this effect.

The assumed SNR characteristics of the four instruments are given in Fig. 2 and are based on instrument noise requirements or provided calibration data. The instrument with lowest spectral resolution tends to have the highest SNR and vice versa, except that OCO-2 has a better SNR than CarbonSat despite its higher resolution. For S-5 P and OCO-2, we have assumed a dependence of the SNR with the square root of the radiance. For CarbonSat, we have assumed a linear dependence with radiance for low radiance levels and a squareroot dependence for higher radiance levels. For GOSAT, we have assumed a weak radiance dependence on the measurement noise with a linear relationship.

The instrument line shape (ILS) function used for OCO2, CarbonSat and S-5 P is a Gaussian function defined by the full width at half maximum (FWHM) given in Table 1. GOSAT uses ILS function which was obtained from the JAXA ILSF model (Kuze et al., 2009). 
Table 1. Assumed instrument parameters in the $\mathrm{O}_{2}$ A-band range for the four instruments used in this study. Resolution is defined by the FWHM of an assumed Gaussian distribution for OCO-2, CarbonSat and S-5 P. GOSAT is as in Kuze et al. (2009).

\begin{tabular}{lllll}
\hline & GOSAT & OCO-2 & S-5 P & CarbonSat \\
\hline Agency & JAXA & NASA & ESA/GMES & ESA \\
Launch year & 2009 & 2014 & 2016 & 2018 \\
Spectral range $(\mathrm{nm})$ & $756-775$ & $757-775$ & $755-775$ & $757-773$ \\
Resolution/FWHM $(\mathrm{nm})$ & 0.03 & 0.044 & 0.5 & 0.1 \\
Sampling per FWHM & 2.5 & 2.5 & 2.5 & 3.0 \\
Number of pixels & 1584 & 1016 & 100 & 480 \\
\hline
\end{tabular}
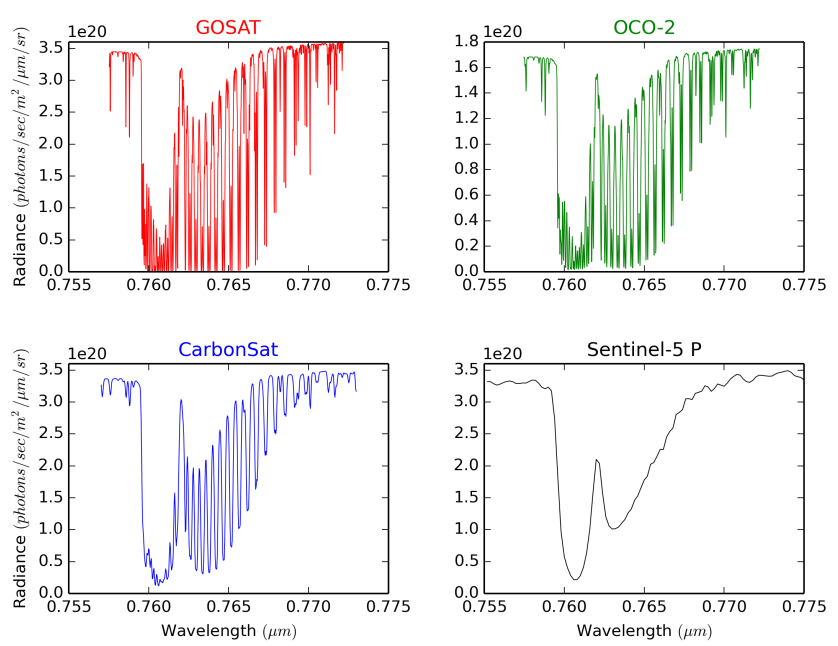

Figure 1. Simulated spectra for GOSAT, OCO-2, CarbonSat and S$5 \mathrm{P}$ for a solar zenith angle of $30^{\circ}$ and a surface albedo of 0.5. An aerosol layer with optical depth of 0.3 at a height of $1 \mathrm{~km}$ with a width of $1 \mathrm{~km}$ is assumed.

\section{Simulation framework}

To assess the aerosol retrieval capabilities for the four instruments we have carried out a series of retrieval simulations based on the instrument configurations as described previously using the forward model of the University of Leicester Full Physics (UoL-FP) retrieval algorithm.

The UoL-FP retrieval utilizes the algorithm developed for the NASA Orbiting Carbon Observation (OCO) mission (Bösch et al., 2006, 2011; Connor et al., 2008; Crisp et al., 2004; Parker et al., 2011). The algorithm has been designed to retrieve $\mathrm{XCO}_{2}$ from SWIR spectra by simultaneously fitting the $0.76 \mu \mathrm{m} \mathrm{O}_{2}$ A-band and the 1.61 and $2.06 \mu \mathrm{m} \mathrm{CO}$ bands (Bösch et al., 2006, 2011; Connor et al., 2008). The algorithm employs an inverse method, where an iterative retrieval system based on Bayesian optimal estimation (maximum likelihood estimation) fits the simulated spectral radiance to the measured spectral radiance in order to infer $\mathrm{XCO}_{2}$ (Rodgers, 2000).

The forward model used to simulate the measured spectra includes solar, radiative transfer and instrument models to simulate the spectral radiance of a scene. We use the low

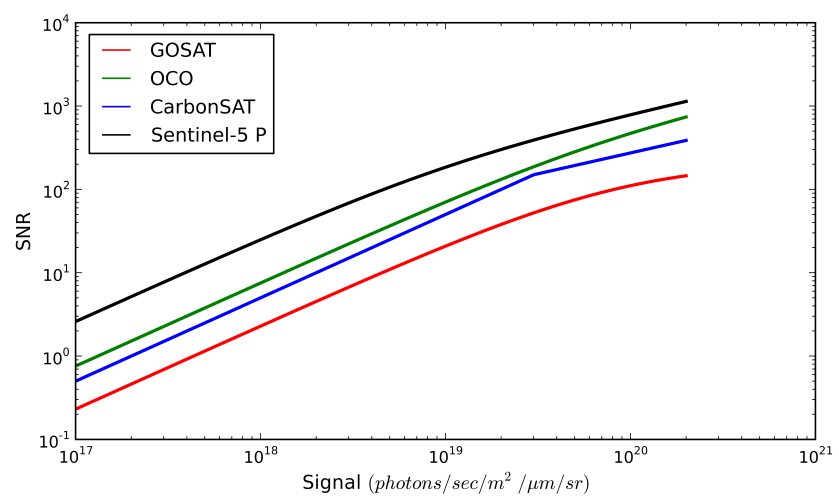

Figure 2. Assumed signal-to-noise (SNR) models for the four instruments GOSAT, OCO-2, CarbonSat and S-5 P.

streams interpolation functionality (O'Dell, 2010) to accelerate the LIDORT radiative transfer model (Spurr et al., 2001), which is combined with a fast 2-orders-of-scattering vector radiative transfer code (Natraj and Spurr, 2007).

We have simulated spectra of the $\mathrm{O}_{2} \mathrm{~A}$-band range for an atmosphere of 39 equally spaced atmospheric pressure levels (spaced by $26.25 \mathrm{mb}$, lowest altitude used is $0.02 \mathrm{~km}$ or $997.5 \mathrm{mb}$ ) for an ECMWF atmosphere in September 2009 over Darwin, Australia, for a range of geophysical scenarios described in Table 2. Albedos of 0.05 and 0.5 have been chosen as extreme values that represent ocean and heavily vegetated land respectively; higher-albedo scenarios were found to behave similarly to the 0.5 case and so were not included. An aerosol extinction profile with a Gaussian-shaped vertical distribution has been assumed for all scenarios using nadir-viewing geometry only for consistency, and it can be expected that the retrieval performance will vary for off-nadir geometry.

All simulations use the same aerosol optical properties which have been calculated as described in Cogan et al. (2012) for the dusty maritime and coarse dust mixture (2b) from Kahn et al. (2001). This external mixture consists of four aerosol components: sulfate, sea salt, accumulation mode and coarse dust (Table 2 in Kahn et al., 2001) with a resulting single scattering albedo of 0.941 at $765 \mathrm{~nm}$ and an Angstrom coefficient of 0.193 . The individual properties of the components such as particle size distribution, shape and refractive index are shown in Table 3 of Kahn et al. (2001). The retrieval utilizes tabulated spectroscopic parameters for $\mathrm{O}_{2}$ taken from v3.2 of the OCO line lists (Crisp et al., 2012).

We have estimated the expected random errors of the retrieved aerosol parameters from the square root of the diagonal elements of the a posteriori covariance matrix $\hat{\mathbf{S}}$, which has been inferred from the a priori covariance matrix $\mathbf{S}_{\mathrm{a}}$, the simulated weighting functions $\mathbf{K}$ (derivatives of the radiance spectrum with respect to the retrieved parameters) and the spectral noise covariance matrix $\mathbf{S}_{\epsilon}$ according to

$\hat{\mathbf{S}}=\left(\mathbf{K}^{T} \mathbf{S}_{\epsilon}^{-1} \mathbf{K}+\mathbf{S}_{\mathrm{a}}^{-1}\right)^{-1}$. 
The averaging kernel matrix, which characterizes the ability of the retrieval to reproduce changes in retrieved parameters, is then given by

$\mathbf{A}=\hat{\mathbf{S}} \mathbf{K}^{T} \mathbf{S}_{\epsilon}^{-1} \mathbf{K}$.

The trace of A provides the so-called degrees of freedom (DoF) for signal which represent the number of independent pieces of information that can be retrieved.

The state vector $\boldsymbol{x}$ that gives the retrieved parameters includes an aerosol extinction profile, an additive offset to the temperature profile, surface albedo and its spectral albedo slope. When stated, an additive intensity offset is also included to mitigate the effects of fluorescence. An intensity offset is only an approximation of the true effect of fluorescence, but, as will be shown later on, the effect is small so that this approximation appears sufficient. Note that fluorescence is not explicitly added to the modelled spectra. The a priori covariance matrix for the aerosol profile retrieval has been generated using the same a priori uncertainties for each level and a correlation length of $2 \mathrm{~km}$ to infer the nondiagonal values of the covariance matrix. The values for the a priori uncertainties of each level have been chosen so that the a priori uncertainty for the total AOD is one, with the AOD here after defined at $765 \mathrm{~nm}$. For the four top-most levels (approximately $80-0.1 \mathrm{mb}, 20-70 \mathrm{~km}$ ) the a priori uncertainty has been set to very small values so that these levels are effectively not retrieved. The a priori uncertainty for surface albedo is 1 so that surface albedo is only very weakly constrained. For the temperature scaling, we have used an a priori uncertainty of $5 \mathrm{~K}$, and for the intensity offset, if retrieved, the uncertainty is $5 \%$ of the continuum. The aerosol extinction given on the 39 levels has been converted into the more commonly used aerosol optical depth per layer (layer aerosol optical depth, LAOD) given on 38 layers.

To calculate the total AOD from the retrieved aerosol extinction profile, we have applied an operator $\boldsymbol{h}$ to the state vector $\boldsymbol{x}$ such that

$\mathrm{AOD}=\boldsymbol{h}^{T} \boldsymbol{x}$

where $T$ is the transpose and $\boldsymbol{h}$ is defined as follows:

$\boldsymbol{h}=\left[\frac{1}{2} \Delta p_{(0,1)}, \Delta p_{(1,2)}, \ldots, \Delta p_{(n-2, n-1)}, \frac{1}{2} \Delta p_{(n-1, n)}\right]$,

with $\left.\Delta p_{(i, i+1)}\right)$ representing the pressure difference between two adjacent levels, $i$ and $i+1$, up to the lowest level (i.e surface pressure), $n$.

The same operation has been used to calculate the optical depth for a height range but with elements of $\boldsymbol{h}$ being set to zero outside of the selected height range. The error $\sigma$ on AOD is then given by

$\sigma^{2}=\boldsymbol{h}^{T} \hat{\mathbf{S}} \boldsymbol{h}$.

The retrieval setup described here is referred to as profile retrieval. In the latter part of this paper we use an alternative aerosol retrieval called the parameter retrieval where the
Table 2. Geophysical parameters used for the retrieval simulations. The aerosol profiles are set up as a Gaussian-shaped distribution for the given value of AOD, height and width with approximate pressure levels.

\begin{tabular}{lc}
\hline Variables & Values \\
\hline SZA & $30^{\circ}, 70^{\circ}$ \\
Surface pressure & $1000 \mathrm{mb}$ \\
Surface albedo & $0.05,0.5$ \\
Atmosphere & $09 / 09-$ Darwin, Aus. \\
\hline Aerosol scenario & AOD, height, width \\
\hline Scenario A: & \\
Boundary-layer aerosol & $0.3,1 \mathrm{~km}(850 \mathrm{mb}), 1 \mathrm{~km}$ \\
Scenario B: & \\
Elevated aerosol i.e dust & $0.3,3 \mathrm{~km}(700 \mathrm{mb}), 1 \mathrm{~km}$ \\
Scenario C: & $0.1,10 \mathrm{~km}(250 \mathrm{mb}), 2 \mathrm{~km}$ \\
Cirrus layer &
\end{tabular}

aerosol profile is parameterised by a Gaussian-shaped profile. In this case, the 39 state vector elements representing the aerosol extinction profile are replaced with three elements: total AOD, layer centre height and layer width. The a priori uncertainty for total AOD is 1 and for centre height $5 \mathrm{~km}$. A very small value for the a priori uncertainty of width has been chosen so that this parameter is highly constrained and it is effectively not retrieved; we do this because the width is otherwise poorly retrieved.

To study systematic effects of incorrect assumptions on aerosol profile, surface pressure and aerosol mixture (Sects. 5.1 and 6), a full end-to-end retrieval of the parameterised aerosol retrieval was used instead of directly calculating the a posteriori error covariance matrix as described previously. Systematic errors have then been estimated from the difference of retrieved and true values for the aerosol parameters.

\section{Aerosol profile retrieval}

\subsection{Single aerosol layer scenarios}

The information content of the aerosol profile retrieval from the $\mathrm{O}_{2}$ A-band is primarily determined by the SNR and the spectral resolution of the instrument. To better understand the dependence on these two instrument parameters, we have carried out simulations for a range of SNRs and resolutions for a generic instrument based on the noise model of S-5 P.

For the simulations we have used a surface albedo of 0.5 , at a solar zenith angle (SZA) of $30^{\circ}$ and aerosol scenario A. We have kept the number of spectral pixels constant for all configurations which results in a high spectral oversampling for configurations with low spectral resolution; this has been done so as not to confuse loss of information with loss of spectral pixels (Frankenberg et al., 2012). 

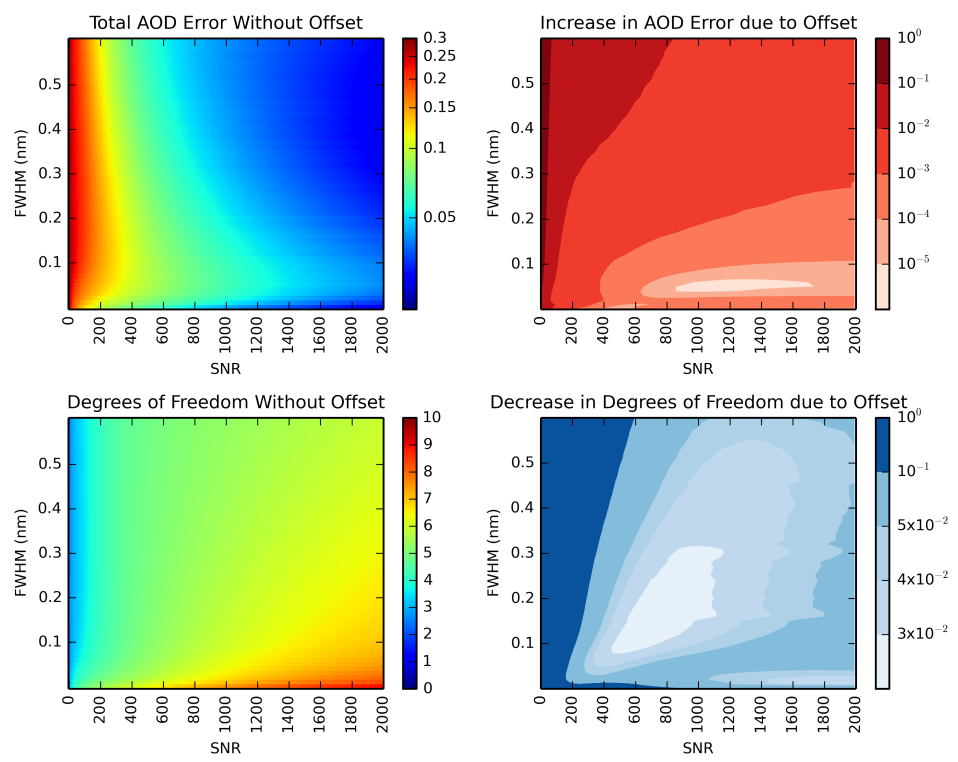

Figure 3. Total AOD error (top left panel) and DoF (bottom left panel) for the aerosol profile retrieval for scenario A; SZA $30^{\circ}$ and albedo 0.5 as a function of continuum SNR and spectral resolution (as given by the FWHM of the ILS) without including an intensity offset in the retrieval. The panels on the right show the change in total AOD error and DoF when including an offset.
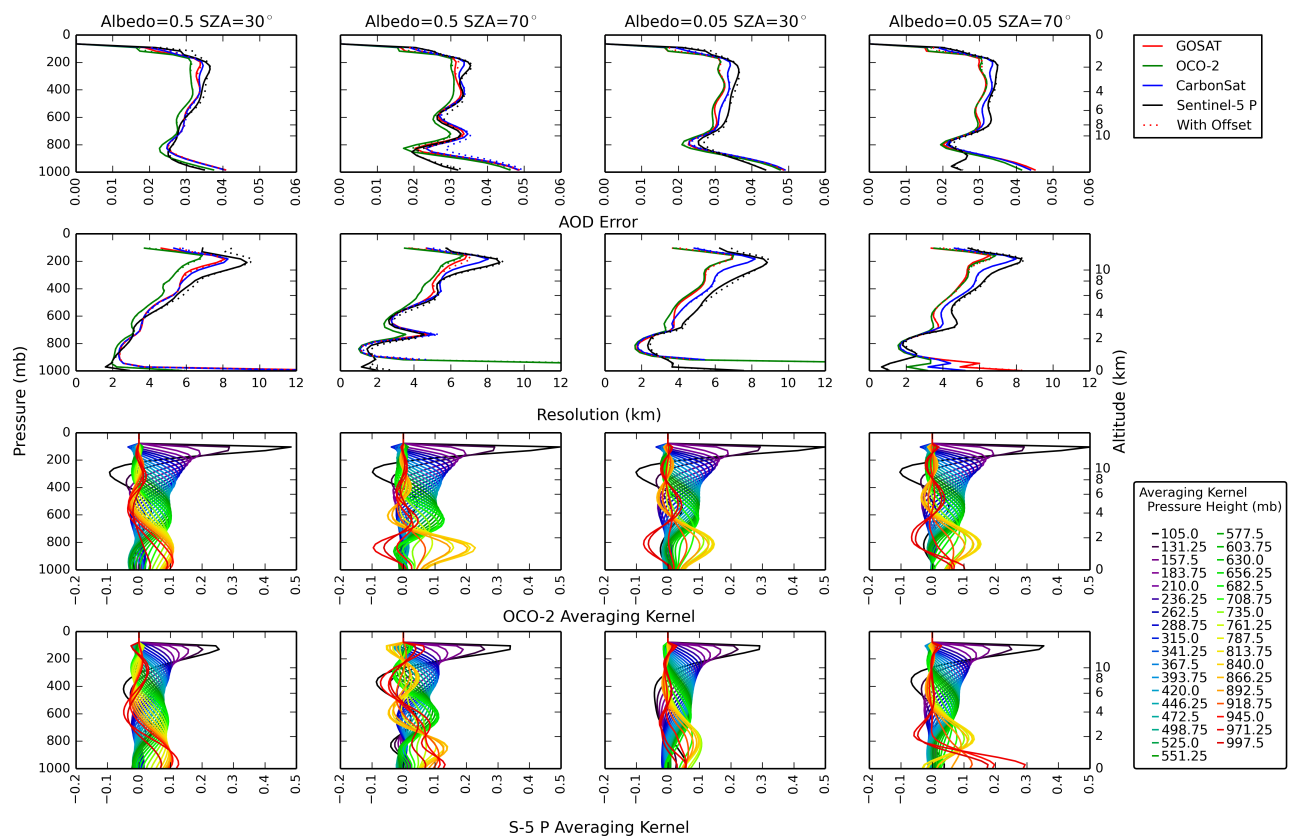

Figure 4. Error of LAOD (top panel) and vertical resolution (middle panel) as a function of pressure for the aerosol profile retrieval for scenario A for surface albedos of 0.05 and 0.5 and SZAs of 30 and $70^{\circ}$ for the four instruments without an intensity offset. The results for a retrieval with intensity offset is shown by the dotted lines. The bottom two rows of panels show the averaging kernels for OCO-2 and S-5 P for the profile retrieval with intensity offset. Note that the top four pressure levels are not shown.

The left panels of Fig. 3 show the error for the total AOD and the DoF as a function of the spectral resolution and continuum SNR for a retrieval without an intensity offset. Note that the DoFs are calculated with respect to the a priori covariance matrix described in Sect. 3 and thus they do not necessarily reflect the true DoFs with respect to the atmospheric 

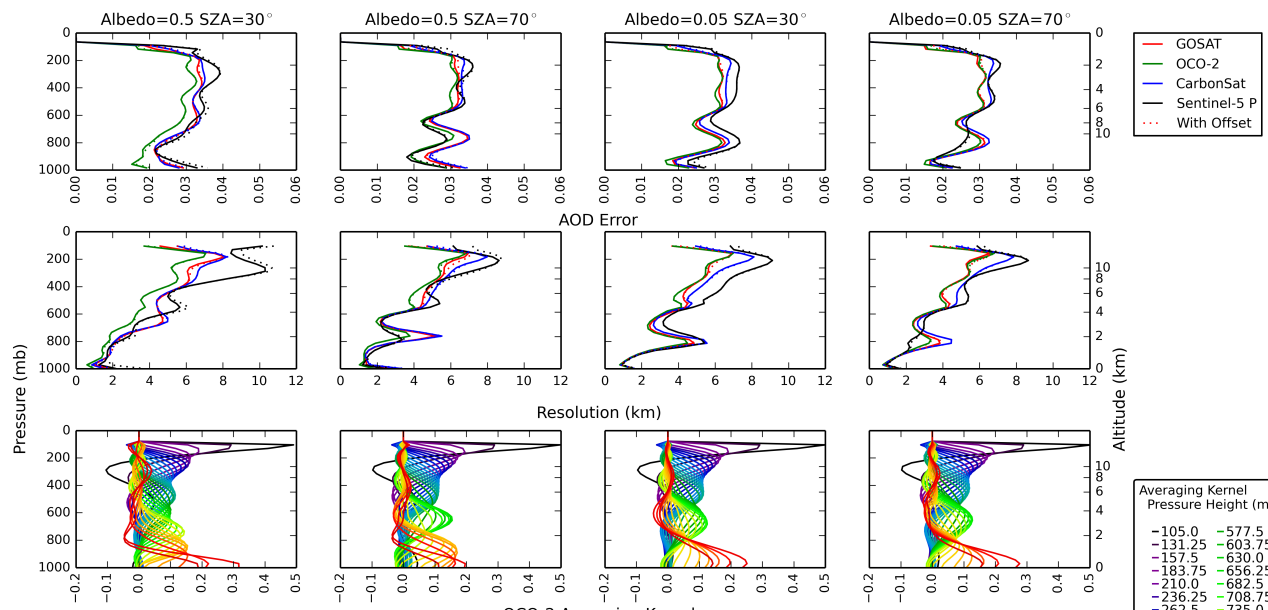

Resolution $(\mathrm{km})$
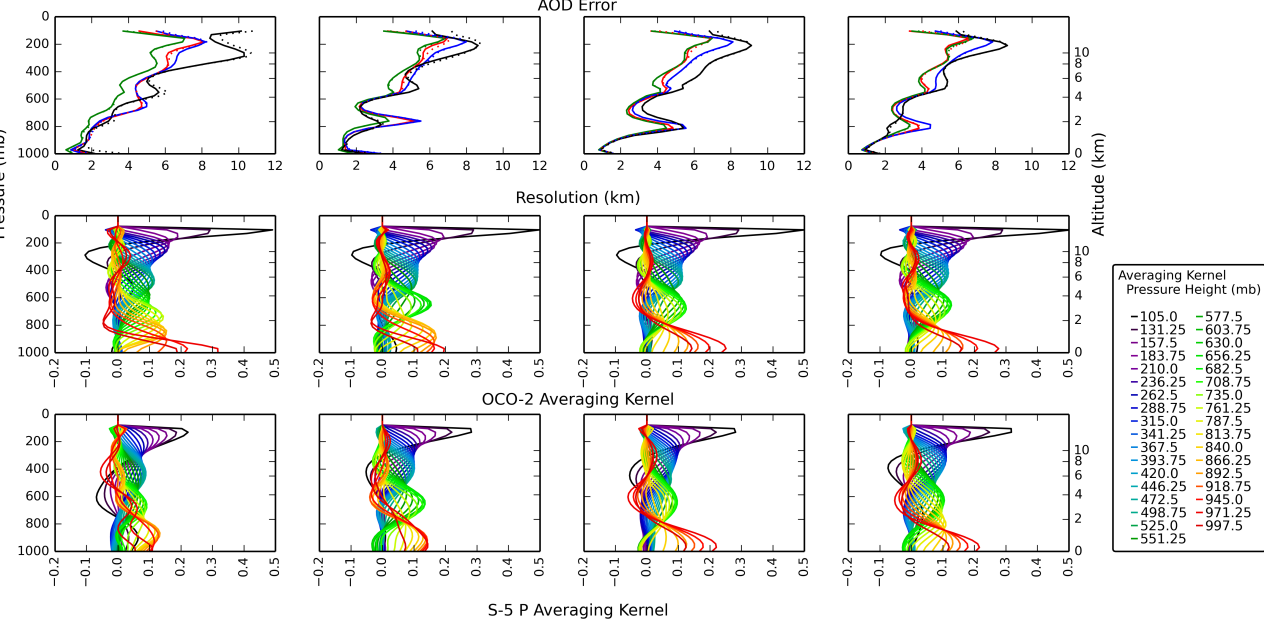

Figure 5. As Fig. 4 but for scenario B.

variability. Instead, they provide a meaningful relative measure for characterizing the ability of different instrumental setups to provide information on the vertical aerosol distribution.

From Fig. 3 we find that a precise retrieval of total AOD does not necessarily require high spectral resolution but does require high SNR. For high values of SNR, the errors tend to be smaller for lower resolution. This is due to the SNR model limiting the usefulness of the higher resolution and therefore lower signals, particularly within the absorption lines and the fact that we have kept the number of spectral points constant for all values of resolution. However, for very high spectral resolution $(0.03 \mathrm{~nm})$, increasing resolution leads to smaller AOD errors regardless of SNR.

As expected, vertical information, shown by the DoFs, shows a clear dependence on the spectral resolution as the vertical information is inferred from the absorption lines of the $\mathrm{O}_{2}$ A-band. For low values of SNR $(<200)$, the noise is limiting the information that can be obtained from the absorption lines and the effect of spectral resolution becomes weak. Consequently, large values for DoF require very high spectral resolution combined with very high SNR.

The impact of including an intensity offset in the retrieval is shown on the right hand side of Fig. 3. The increase in the error for total AOD is typically small with an average value of $5 \times 10^{-3}$. The largest increase is observed for low SNR, and the smallest effect is found for high-resolution and modest-to-high SNR. For DoF, we observe a small decrease of 0.05 on average. Again at low SNR the loss in information is more substantial and can be up to a $50 \%$ decrease in DoFs for very low values of SNR.
Based on Fig. 3, we can make several tentative predictions for the performance of the four instruments described in Sect. 2. Firstly, we expect S-5 P to behave somewhat differently from the other three instruments due to it operating in the low-resolution and high-SNR regime that should result in low total AOD errors but also low DoFs. OCO-2 has high spectral resolution and high SNR, so it should achieve high DoFs together with small total AOD errors. GOSAT has very high spectral resolution but lower SNR such that the values for DoFs will be lower and for the total AOD error higher. CarbonSat has lower spectral resolution but higher SNR than GOSAT, which should lead to a similar performance. All four instruments should not be substantially affected by the inclusion of an intensity offset in the retrieval. It can be expected that DoFs will be around 4 to 5 and AOD errors might exceed a value of 0.05 , especially for GOSAT and CarbonSat.

We now study the performance of the four instruments in Figs. 4 and 5 for scenarios A and B as described in Table 2 using the spectral and noise properties of the instruments as given in Table 1.

The LAOD error, shown in the top row of Figs. 4 and 5 , is typically between 0.02 and 0.04 at pressures of 200 to $800 \mathrm{mb}$. Layers represent roughly $26 \mathrm{mb}$ each with typically smallest errors for OCO-2 and largest errors for S-5P. For scenario A, errors tend to increase significantly below $800 \mathrm{mb}$ due to correlations between surface albedo and the aerosol residing near the surface. However, instruments with low spectral resolution (S-5 P) tend to behave differently from the instruments with higher spectral resolution, with the low-resolution instrument showing a weaker increase in error towards the surface, especially for large SZA. This is a result 


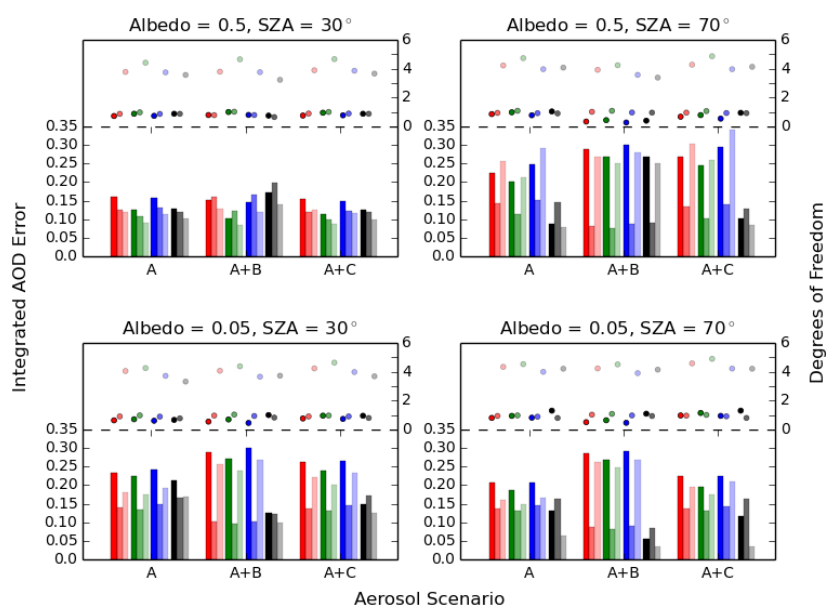

Figure 6. AOD error and DoF for the aerosol profile retrieval for surface albedos of 0.05 and 0.5 and SZAs of 30 and $70^{\circ}$ for the four instruments. Errors are integrated over the $0-2$ and $2-5 \mathrm{~km}$ ranges as well as the total column for aerosol scenario $\mathrm{A}$ and combined aerosol scenarios A + B and A + C. Intensity offset is included.

of saturation effects in the aerosol weighting functions near the line centres for low altitude for high spectral resolution.

For scenario B, such a clear increase in error with decreasing altitude is not observed as the bulk of the aerosol in this simulation is in the free troposphere, resulting in less saturation of the Jacobians and weaker correlations to the surface albedo.

The impact of including an intensity offset is fairly minor. A slight increase in errors can be observed that is most pronounced for CarbonSat and S-5 P using scenario A.

The middle panels of Figs. 4 and 5 show the vertical resolution of the aerosol profile retrieval as a function of altitude, where we define the resolution by the reciprocal of the trace of the averaging kernels multiplied by the pressure grid and converted into kilometres as in Purser and Huang (1993).

On average the resolution is $4.5 \mathrm{~km}$ with the resolution becoming substantially poorer for high altitude. For scenario A, the vertical resolution increases from $2 \mathrm{~km}$ at $800 \mathrm{mb}$ to $6-10 \mathrm{~km}$ at $200 \mathrm{mb}$ pressure for all four instruments. For S-5 $\mathrm{P}$ the resolution remains similar near the surface, while for the other instruments the resolution decays rapidly at low altitude. For scenario B, the best resolution is observed near the surface with values approaching $1 \mathrm{~km}$ for all instruments and the average resolution improves to $4 \mathrm{~km}$.

Similar to the LAOD errors, OCO-2 has typically the highest vertical resolution in the free troposphere. S-5 P typically outperforms all other instruments near the surface but often shows the worst vertical resolution near the free and upper troposphere.

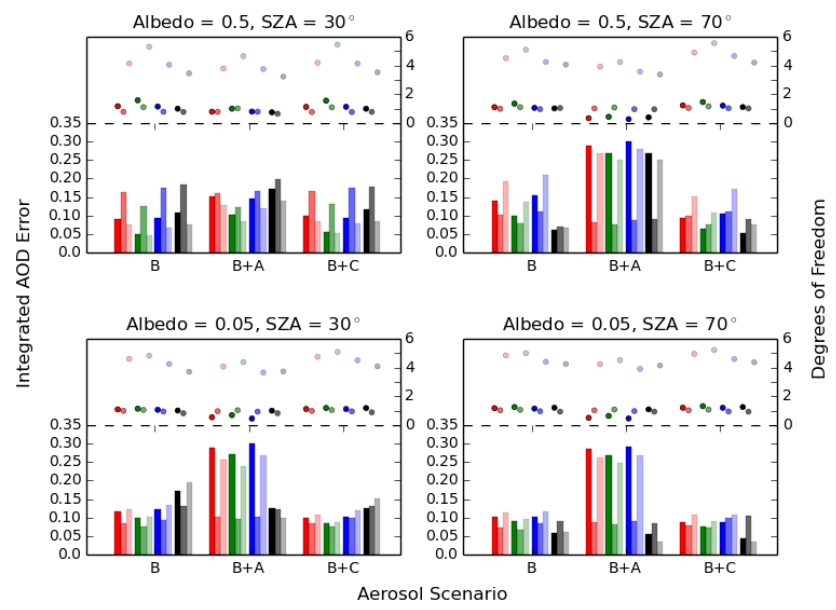

Figure 7. As Fig. 6 but for the aerosol scenario B and combined aerosol scenarios $\mathrm{B}+\mathrm{A}$ and $\mathrm{B}+\mathrm{C}$. Note that scenario $\mathrm{B}+\mathrm{A}$ is identical to A + B from Fig. 6 .

The averaging kernels for the aerosol profile retrieval for OCO-2 and S-5 P are given in the bottom panels of both figures. As expected, the averaging kernels are relatively broad which reflects the limited vertical resolution. Between 200 and $600 \mathrm{mb}$, the peak roughly corresponds to the associated pressure height, while below and above we often find that averaging kernels overlap. Overall, the averaging kernels suggest that it may be possible to resolve 3-4 layers within the atmosphere. The figures also further demonstrate the better sensitivity nearer to the surface for S-5 P, particularly at higher SZA.

As the effect of an intensity offset is small in both scenario $\mathrm{A}$ and $\mathrm{B}$, all further retrieval simulations include intensity offset in the retrieval as it will provide a more realistic assessment of aerosol retrievals over vegetated land.

For a more quantitative comparison, we have integrated the LAOD profile over the height range between 0 and $2 \mathrm{~km}(\sim 1000-750 \mathrm{mb})$ to represent roughly the range of the boundary layer, over 2 to $5 \mathrm{~km}(\sim 750-500 \mathrm{mb})$ to represent the lower free troposphere and over the full atmosphere to obtain total AOD. The AOD errors and DoFs for the three height ranges are given in Figs. 6 and 7 for the scenarios $\mathrm{A}$ and $\mathrm{B}$ respectively. Scenarios labelled $\mathrm{A}+\mathrm{B}, \mathrm{A}+\mathrm{C}$ or $\mathrm{B}+\mathrm{C}$ include two aerosol layers and they will be discussed in Sect. 4.2.

For scenario A (Fig. 6), we find that AOD errors for the 0-2 km range are consistently lowest for S-5 $\mathrm{P}$ with errors between 0.09 and 0.21 . The superior retrieval performance of S-5 P is most pronounced for large SZAs, whereas for lower SZAs the errors for the four instruments become more similar, with errors for OCO-2 approaching those obtained for S-5 P. DoFs range from 0.62 (CarbonSat for SZA of $30^{\circ}$ and albedo of 0.05 ) to 1.35 (S-5 $\mathrm{P}$ for SZA of $70^{\circ}$ and albedo of 0.5 ) but are mostly slightly less than one, which means that AOD for this height range cannot be independently re- 
trieved. For the $2-5 \mathrm{~km}$ range, we find the lowest errors and largest DoFs for OCO-2, with errors between 0.11 and 0.13 and DoFs close to 1 . For S-5 P, errors are particularly large for the low-albedo cases. As expected, we find that results for CarbonSat and GOSAT are similar to each other. For total AOD, the retrievals for the four instruments compare in a similar manner as for the $0-2 \mathrm{~km}$ range, with errors ranging from 0.06 up to 0.29 . This represents a significant reduction in error compared to the a priori uncertainty of 1 for all cases. Note that the errors for total AOD are often smaller than the errors for the $0-2$ or $2-5 \mathrm{~km}$ height range, owing to the presence of negative correlations between layers. The DoFs for the full range are between 3.3 to 4.7 , with the highest values for OCO-2 and the lowest values for S-5 P and CarbonSat.

As has been discussed above, the retrieval of aerosol vertical information depends on the surface albedo. At low albedo, aerosols act to shorten the path length and at high albedo they tend to lengthen the path length with a transition in-between where aerosols will have little to no impact on the radiance. We find that aerosol weighting functions become small for a surface albedo of $\sim 0.2$ and retrieval errors increase accordingly. Due to the modulation of this coupling between aerosol scattering and surface with the spectrally variable $\mathrm{O}_{2}$ absorption, the weighting functions differ from zero and the increase in AOD error is modest.

For scenario B (Fig. 7), the AOD errors for the 0-2 and the $2-5 \mathrm{~km}$ range tend to be much smaller for all instruments compared to scenario A, with the exception of the case of high albedo and low SZA. The retrieval performance for S$5 \mathrm{P}$ varies largely with SZA, with lowest errors of around 0.05 for SZA of $70^{\circ}$ and highest errors with values between 0.1 and 0.18 for SZA of $30^{\circ}$. For the low SZA case, OCO-2 gives the smallest AOD errors for the $2-5 \mathrm{~km}$ height range, where the bulk of the aerosol resides in these simulations, with values ranging from 0.08 to 0.12 .

The AOD errors will be a composite of the error due to the measurement noise and the so-called smoothing error which reflects the errors introduced by the limited vertical resolution of the observations and the smoothing of the a priori constraint (Rodgers, 2000). We have estimated the smoothing errors for the different instruments using the a priori covariance matrix to represent the atmospheric variability of an ensemble of scenes. This will certainly lead to an overestimation of true smoothing errors for most scenarios as the assumed uncertainty of the aerosol a priori covariance matrix is very large with a standard deviation of the total AOD of one (see Sect. 3). For scenario A, the estimated smoothing errors are significant with values of about 35 to $55 \%$ of the total AOD error for GOSAT, OCO-2 and CarbonSat and 30 to $40 \%$ for S-5 P. The estimated smoothing errors significantly decrease for scenario B with values of 13 to $30 \%$ for GOSAT, OCO-2 and CarbonSat and larger values of 32 to $42 \%$ for S-5 P.

To illustrate the effect of the height of the aerosol layer on the aerosol retrieval, the error of the total AOD has been
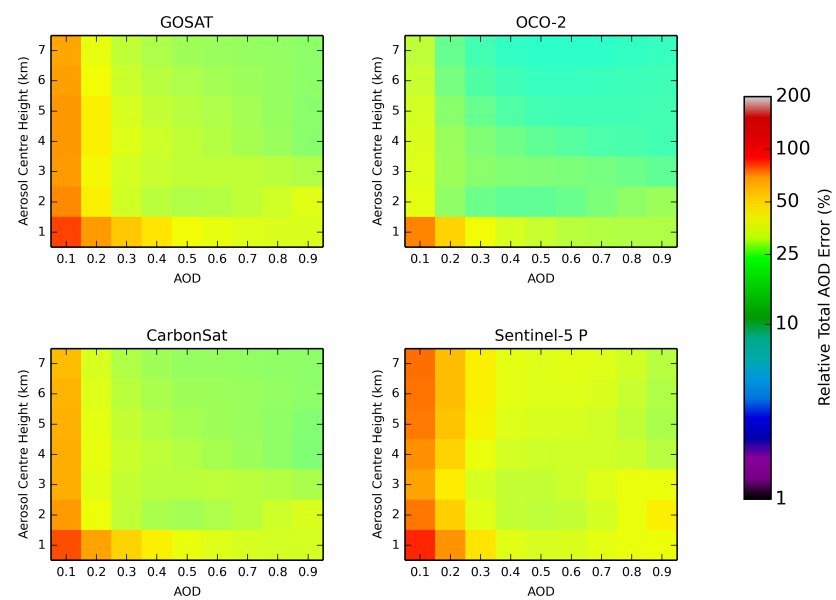

Figure 8. Total AOD error (given as a relative error) as a function of aerosol centre height and AOD for the four instruments for a SZA of $30^{\circ}$ and albedo of 0.5 . Intensity offset is included in the retrieval.

calculated as a function of centre layer height ranging from 1 to $7 \mathrm{~km}(\sim 850-400 \mathrm{mb})$ and the total AOD ranging from 0.1 to 0.9 for the case of SZA of $30^{\circ}$ and albedo of 0.5 . As shown by Fig. 8, a clear decrease in relative error with increasing total AOD and with increasing height can be observed. As the AOD increases to much higher values, the errors tend to then increase again. This is caused by two opposing effects: an increase in sensitivity of the aerosol retrieval with aerosol weighting functions showing larger values with increasing AOD and a decrease in SNR with increasing AOD due to the high surface albedo.

This figure further emphasises the difficulty in retrieving aerosol that is present near the surface. Errors can be around $100 \%$ for typical values of background AOD ( 0.1$)$. OCO2 tends to perform significantly better than the other three instruments with errors in the range of 20-25\% if the centre height is $2 \mathrm{~km}$ or higher. With increased layer height, the observed AOD error from GOSAT and CarbonSat are also smaller than those from S-5 P. Note that for a scenario with large SZAs, the performance of S-5 P would improve considerably compared to the case shown in Fig. 8.

\subsection{Double aerosol layer scenarios}

So far we have only included scenarios with a single aerosol layer in the atmosphere, but in reality multiple aerosol layers will often be present, such as an elevated dust layer present above boundary-layer aerosol. Furthermore, a high-altitude cirrus layer can be present above an aerosol layer, especially in the tropics. Here, we study the performance of the aerosol profile retrieval for the four instruments, for scenarios that combine an aerosol layer in the boundary layer (scenario A), an elevated layer in the free troposphere (scenario B) and a cirrus cloud layer (scenario $\mathrm{C}$ ). 
Figure 6 shows the AOD error for the $0-2$ and $2-5 \mathrm{~km}$ ranges, as well as the total AOD error for the combined scenarios $\mathrm{A}+\mathrm{B}$ and $\mathrm{A}+\mathrm{C}$.

Compared to scenario $\mathrm{A}$, the additional layer of scenario $\mathrm{A}+\mathrm{B}$ leads to an increase in the AOD error of $0.05-0.1$ for the $0-2 \mathrm{~km}$ range for GOSAT, OCO-2 and CarbonSat, except for the low-SZA and high-albedo case where little change is seen. A very significant increase in the AOD error for the 0 $2 \mathrm{~km}$ range is also found for $\mathrm{S}-5 \mathrm{P}$ for high albedo, whereas the opposite behaviour is found for low albedo with a large decrease in the AOD error by $\sim 50 \%$; this an be simply described by the SNR decreasing and increasing in each case respectively, whereas for the other instruments they are again hampered by Jacobian saturation.

The errors for the $2-5 \mathrm{~km}$ range are reduced for all instruments to values between $0.07-0.12$, except for the low-SZA and high-albedo case.

Adding a high-altitude cirrus cloud (scenario C) has less impact on the AOD retrieval than adding the free tropospheric aerosol layer (scenario B). For the scenario A $+\mathrm{C}$, the error for the $0-2 \mathrm{~km}$ range increases by up to 0.05 for GOSAT, OCO-2 and CarbonSat. For S-5 P, we find that the AOD error for the $0-2 \mathrm{~km}$ range is slightly decreased for low albedo and is almost unchanged for high albedo, which might reflect a weaker sensitivity of S-5 P to the upper atmosphere.

Figure 7 demonstrates the impact of additional aerosol layers for scenario $\mathrm{B}$, noting that scenario $\mathrm{B}+\mathrm{A}$ is the same as scenario A $+B$ shown in Fig. 6. Comparing scenario B + A to scenario $\mathrm{B}$ we see that the additional aerosol layer has far less impact than in the previous case, where an additional aerosol layer was added to scenario A.

The most noticeable variations for the $2-5 \mathrm{~km}$ range occur for the high-albedo cases where the error reductions, and error increases in the case of S-5 P, are between 0.001 and 0.025 . In contrast, the total AOD error varies substantially in comparison to the single aerosol for the scenario $\mathrm{B}+\mathrm{A}$ case (0.05-0.2), producing a greater relative change than in the previous example. The addition of an extra layer does not significantly effect the DoFs within the $2-5 \mathrm{~km}$ range, where values are consistently 1 , though a drop is noticeable for the $0-2 \mathrm{~km}$ and total column.

For scenario $\mathrm{B}+\mathrm{C}$ we see very little increase in errors for all instruments and typically a minor reduction in the 0 $2 \mathrm{~km}$ range and total error, particularly at high albedo and $\mathrm{SZA}$, whereas the $2-5 \mathrm{~km}$ range does not show the same degree of variability. S-5 $\mathrm{P}$ shows the greatest reduction of the four, particularly at low albedo and high SZA. The DoFs mirror this behaviour by only very slight fluctuations across all ranges, instruments and scenes. The impact of a cirrus layer is clearly weaker when the aerosol is higher in the atmosphere and thus more disentangled from the surface.

\section{Constraining the aerosol retrieval}

\subsection{Parameter retrieval}

An alternative method for the aerosol retrieval is to retrieve a small number of parameters of an assumed profile shape instead of retrieving a full extinction profile. This means that we replace the soft constraint on the aerosol profile imposed by the a priori covariance matrix with a hard constraint given by an assumed profile shape. We assume a Gaussian function for the vertical distribution of aerosol optical depth that is defined by the total AOD, centre height and width so that the 39 parameters related to the aerosol extinction profile are replaced with two retrieved parameters only (note that width is effectively not retrieved). Accordingly, the retrieval precision for the two parameters will be higher compared to the 39 parameters of the full profile retrieval.

We have calculated the errors on the retrieved AOD and centre height for the four instruments for the same scenarios as before.

Comparing the AOD error of the parameter retrieval (Table 3) to the total AOD error from the profile retrieval (Figs. 6 and 7), we find that errors are much reduced in almost all cases for scenario B, whereas for scenario A the errors are comparable for high albedo but much increased for scenarios with low albedo, with errors up to 0.57 . This is not surprising, as the extinction that is retrieved as a profile is collapsed into the total AOD, which corresponds to a single parameter, whereas for the parameterised retrieval two parameters are obtained. Interestingly, the AOD error for the parameterised retrieval for the boundary-layer scenario (scenario A) with low albedo even exceeds the AOD error for the $0-2 \mathrm{~km}$ range from the profile retrieval. Similar to the profile retrieval, the AOD errors for scenario A are smallest for S-5 P, except for low SZA and high albedo. AOD errors for scenario A tend to be large, and only for S-5 P (for large SZA) and OCO-2 (for low SZA and high albedo) do errors approach a value of 0.05 or less. AOD errors for scenario B are well below 0.05 for GOSAT and OCO-2 as well as for CarbonSat except for low SZA and high albedo, where for S-5 P errors tend to be much higher.

The error for the centre height tends to be correlated with the AOD error and are typically small, with values around a few hundred metres. For scenario A and low albedo, the errors can exceed $1 \mathrm{~km}$, with the largest errors found for CarbonSat and GOSAT.

Figure 9 shows the AOD error for the four instruments as a function of aerosol centre height and AOD for a SZA of $30^{\circ}$ and albedo of 0.5 similar to the profile retrieval in Fig. 8. As discussed, the structure is caused by increasing information content and decreasing SNR with increasing AOD and with decreasing sensitivity to the $3-4 \mathrm{~km}$ when the aerosol is above or below this height.

For this high-albedo case shown in the figure, we find that the AOD error from the parameterised retrieval yields signif- 

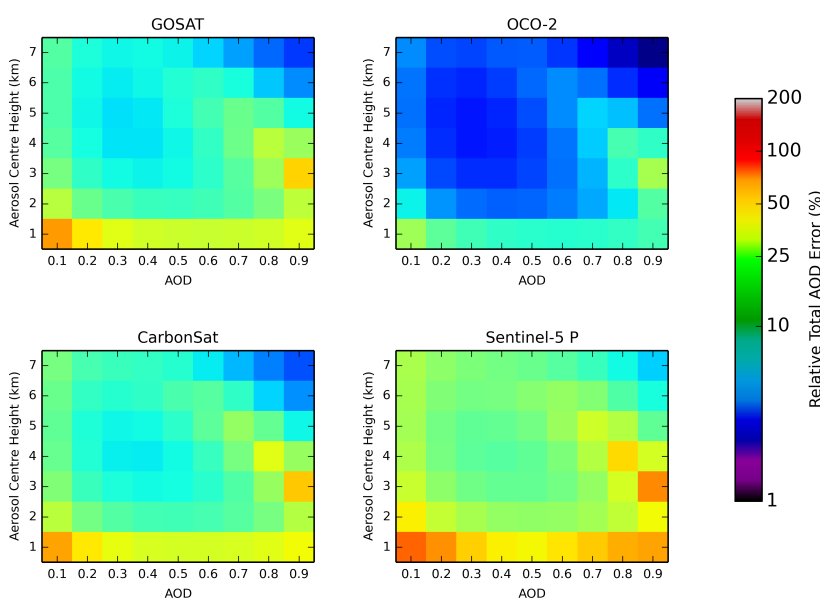

Figure 9. Relative AOD error as a function of aerosol centre height and AOD for the parameterised aerosol retrieval for a SZA of $30^{\circ}$ and albedo of 0.5 . Intensity offset is included.

icantly smaller errors compared to the profile retrieval, especially if the aerosol centre height is $2 \mathrm{~km}$ or higher. AOD errors for the parameterised retrieval remain small even for low AODs with errors less than $10 \%$ for OCO-2 for aerosols with centre heights above $1-2 \mathrm{~km}$. In particular for S-5 P, the AOD errors in the parameterised and profile retrievals converge if the aerosols are near the surface.

The parameterised retrieval assumes a certain shape of the aerosol profile and any deviations from the assumed profile shape can result in biases in the retrieved AOD and centre height. To assess this effect, we have simulated scenarios that include two aerosol layers or one aerosol layer and a cirrus cloud and then retrieved them with the parameterised retrieval for a single aerosol layer using the full end-to-end retrieval. The a priori information for the retrieval has been taken from the lower aerosol layer of each simulated scenario.

Figure 10 shows the retrieved AODs and centre heights for simulated scenarios $\mathrm{A}+\mathrm{B}, \mathrm{A}+\mathrm{C}$ and $\mathrm{B}+\mathrm{C}$.

The total AOD for Scenario A + B is 0.6 with layers at 1 and $3 \mathrm{~km}$, which appears to be well reproduced by all instruments for the high-albedo and low-SZA case. The retrieved height is around $2 \mathrm{~km}$, representing the mean of the two aerosol layers in the simulation. For all other cases, OCO-2, GOSAT and CarbonSat appear mostly sensitive to the upper aerosol layer, and thus the total atmospheric AOD is underestimated. S-5 P shows some sensitivity to the lower layer and retrieved AOD values are consistently larger and retrieved heights lower compared to the other three instruments.

For the scenario $\mathrm{A}+\mathrm{C}$ that combines boundary layer aerosol with a cirrus cloud, we find that retrieved AOD and height vary substantially from case to case and for the different instruments. Again, for the high-albedo and low-SZA case, the retrieved AOD reproduces approximately the true AOD of 0.4 and the retrieved height represents roughly a
Table 3. Errors of retrieved AOD (top) and height (bottom) for the parameterized aerosol retrieval for aerosol scenarios A and B. Intensity offset is included.

\begin{tabular}{lcccc}
\hline & \multicolumn{4}{c}{ AOD error } \\
\cline { 2 - 5 } & GOSAT & OCO-2 & CarbonSat & S-5 P \\
\hline Scenario A & & & & \\
Albedo $=0.5, \mathrm{SZA}=30^{\circ}$ & 0.082 & 0.029 & 0.084 & 0.117 \\
Albedo $=0.5, \mathrm{SZA}=70^{\circ}$ & 0.266 & 0.150 & 0.258 & 0.057 \\
Albedo $=0.05, \mathrm{SZA}=30^{\circ}$ & 0.502 & 0.426 & 0.571 & 0.275 \\
Albedo $=0.05, \mathrm{SZA}=70^{\circ}$ & 0.375 & 0.288 & 0.369 & 0.053 \\
\hline Scenario B & & & & \\
Albedo $=0.5, \mathrm{SZA}=30^{\circ}$ & 0.045 & 0.025 & 0.070 & 0.112 \\
Albedo $=0.5, \mathrm{SZA}=70^{\circ}$ & 0.032 & 0.018 & 0.035 & 0.055 \\
Albedo $=0.05, \mathrm{SZA}=30^{\circ}$ & 0.026 & 0.019 & 0.035 & 0.064 \\
Albedo $=0.05, \mathrm{SZA}=70^{\circ}$ & 0.021 & 0.018 & 0.037 & 0.023 \\
\hline & & Height error $(\mathrm{km})$ & \\
\cline { 2 - 5 } & GOSAT & OCO-2 & CarbonSat & S-5 P \\
\hline Scenario A & & & & \\
Albedo $=0.5, \mathrm{SZA}=30^{\circ}$ & 0.265 & 0.095 & 0.259 & 0.371 \\
Albedo $=0.5, \mathrm{SZA}=70^{\circ}$ & 0.651 & 0.367 & 0.671 & 0.157 \\
Albedo $=0.05, \mathrm{SZA}=30^{\circ}$ & 1.442 & 1.225 & 1.649 & 0.838 \\
Albedo $=0.05, \mathrm{SZA}=70^{\circ}$ & 1.005 & 0.774 & 0.987 & 0.175 \\
\hline Scenario B & & & & \\
Albedo $=0.5, \mathrm{SZA}=30^{\circ}$ & 0.177 & 0.060 & 0.179 & 0.319 \\
Albedo $=0.5, \mathrm{SZA}=70^{\circ}$ & 0.270 & 0.156 & 0.334 & 0.441 \\
Albedo $=0.05, \mathrm{SZA}=30^{\circ}$ & 0.242 & 0.183 & 0.434 & 0.376 \\
Albedo $=0.05, \mathrm{SZA}=70^{\circ}$ & 0.216 & 0.168 & 0.364 & 0.090 \\
\hline & & & & \\
\hline
\end{tabular}

weighted average value of the two layers in the simulation. For all other cases, a centre height and AOD resembling those of cirrus layer are observed for instruments with high spectral resolution (OCO-2 and GOSAT), while for S-5 P and CarbonSat the retrieved height and AOD are more variable, with sensitivity to both layers.

For scenario $\mathrm{B}+\mathrm{C}$, we find that results for all four instruments are very similar to each other with a tendency to overestimate the total AOD for high albedo and low SZA and to underestimate AOD for all cases. The retrieved height tends to represent or somewhat overestimate the average height except for the high-albedo and low-SZA case, where the retrieved height is the height of the lower layer.

\subsection{Albedo constraints}

For the aerosol retrieval, we have imposed only a very weak constraint on surface albedo with an a priori uncertainty of 1. As already discussed in the previous sections, the errors for the AOD retrieval are especially large when the aerosol is near the surface due to strong correlations between AOD near the surface and surface albedo. Imposing a much tighter constraint on surface albedo will help to reduce these correlations, which will then lead to an improved precision of the AOD retrieval. 

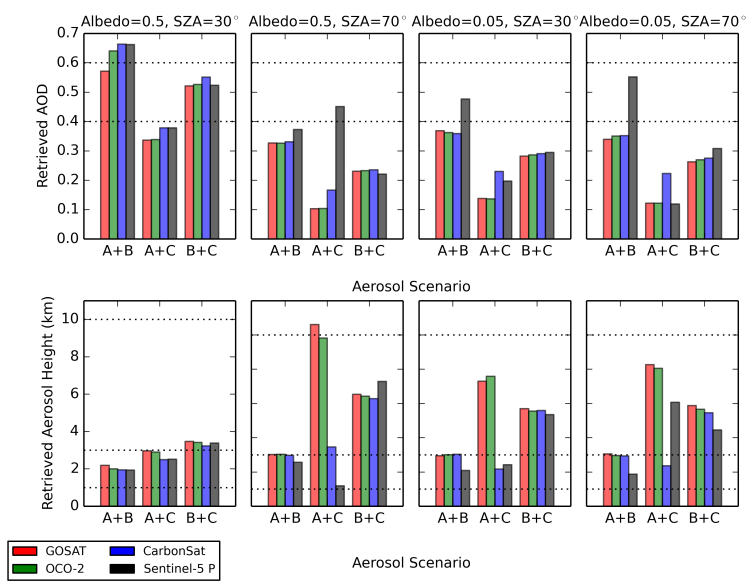

Figure 10. AOD and height errors for the parameterised aerosol retrievals for the combined aerosol scenarios $\mathrm{A}+\mathrm{B}, \mathrm{A}+\mathrm{C}$ and $\mathrm{B}+\mathrm{C}$. In the top row the horizontal lines indicate the true AOD values for each case, i.e. the sum of both layers. In the bottom row they show the heights of each individual layer as a reference noting that the prior value for each scenario is the lowest layer height.

To investigate the potential benefit of albedo constraints, a series of retrieval simulations with varying levels of albedo constraint have been carried out.

The inferred errors of the total AOD for scenario A are shown in Fig. 11. As expected, we find that the error for the AOD retrieval decreases with increasing constraint on the surface albedo, but significant improvements in the errors are only obtained once the assumed albedo a priori uncertainty falls below a certain threshold. In the high-albedo case for OCO-2, CarbonSat and GOSAT, this threshold is around 0.1 (or $20 \%$ ) for a SZA of $70^{\circ}$, though it reduces to 0.01 (or $2 \%$ ) for a SZA of $30^{\circ}$. Again, we find that S-5 P behaves differently and a stronger constraint on the surface albedo is needed for the high-albedo cases. For the low-albedo case, the threshold is between 0.01 and 0.03 (20 to $60 \%$ ).

Overall, we find that constraining the surface albedo will help to reduce the errors of the AOD retrieval, but the required level of a priori knowledge of the surface albedo is very variable and can be very high for some scenarios.

\section{Retrieval assumptions}

\subsection{Surface pressure and temperature}

In the retrieval simulations so far, we have assumed that the surface pressure is sufficiently well known and would not need to be retrieved. To assess the impact of a potential bias in surface pressure on the retrieved aerosol parameters, we have simulated spectra for scenario A with a surface albedo of 0.5 and a SZA of $30^{\circ}$. The spectra have then been retrieved using the full end-to-end retrieval, with the parameterised
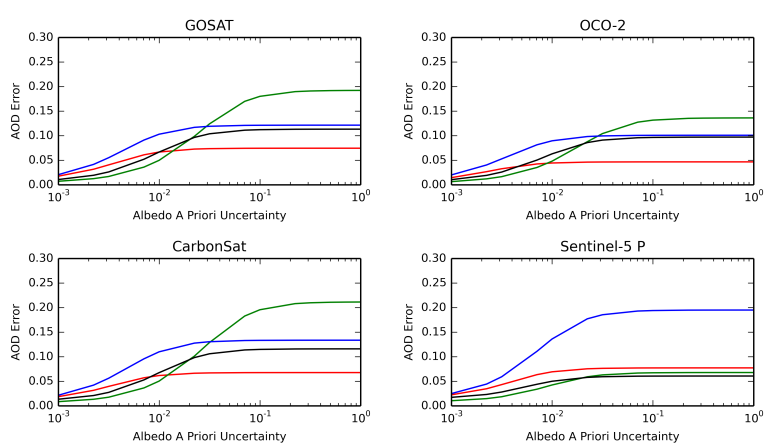

\begin{tabular}{|ll|} 
- & Albedo $=0.5, \mathrm{SZA}=30^{\circ}$ \\
- & $\mathrm{SZA}=70^{\circ}$ \\
- & Albedo $=0.05, \mathrm{SZA}=30^{\circ}$ \\
- & $\mathrm{SZA}=70^{\circ}$ \\
\hline
\end{tabular}

Figure 11. Total AOD error for the aerosol profile retrieval for scenario A for different albedo constraints given by the a priori uncertainty.

aerosol retrieval as described in Sect. 3, but with a systematic bias in surface pressure of $2 \mathrm{mb}$. The resulting biases in AOD and height are shown in Table 4.

Overall, we find that instruments with higher spectral resolution coupled with SNR are less sensitive to biases in surface pressure. A $2 \mathrm{mb}$ bias in surface pressure results in a $0.1(30 \%)$ bias in retrieved AOD for S-5 P, CarbonSat and GOSAT and of 0.07 (23\%) for OCO-2. The bias in height is typically less. For a $2 \mathrm{mb}$ surface pressure bias, a $200 \mathrm{~m}$ or more bias in retrieved height is obtained for S-5 P, CarbonSat and GOSAT, whilst a bias of only $70 \mathrm{~m}$ is obtained for OCO-2.

An additive temperature-scaling factor is a retrieved parameter, but the retrieval of aerosol is still subject to potential errors caused by a systematic difference in the shape of the atmospheric temperature profile. To assess this effect, a perturbation of $1 \mathrm{~K}$ has been added to the bottom kilometre of the assumed atmospheric profile before performing the retrieval. The inferred biases in AOD and height for the same scenario as above are given in Table 4. Overall, we find that biases are small: the largest bias for S-5 P is 0.02 for AOD and of $74 \mathrm{~m}$ for height. Similarly to surface pressure, we find that instruments with high resolution are less affected and biases are an order of magnitude smaller compared to S-5 P.

\subsection{Aerosol mixture}

All retrieval simulations so far have assumed that the aerosol mixture is known. Usually this is not the case and wrong assumptions on the aerosol mixture can result in systematic errors in the retrieved aerosol parameters. Again, we have simulated spectra for scenario A for a surface albedo of 0.5 and a SZA of $30^{\circ}$. We have used the full end-to-end retrieval to retrieve the simulated spectra generated using the dusty maritime and course dust mixture (mixture $2 b$ ) and carried out 
Table 4. Biases in retrieved AOD and height (in $\mathrm{km}$ ) due to a surface pressure bias $\left(\Delta P_{\text {surf }}\right)$ of $2 \mathrm{mb}$, a temperature bias $\left(\Delta T_{0-1 \mathrm{~km}}\right)$ of $1 \mathrm{~K}$ for the altitude range of $0-1 \mathrm{~km}$ and assumptions in aerosol mixture. The aerosol mixtures are given in parentheses using the nomenclature from Kahn et al. (2001). The reference aerosol mixture used in the simulations is mixture $2 \mathrm{~b}$.

\begin{tabular}{lcccc}
\hline & \multicolumn{5}{c}{ AOD and height $(\mathrm{km})$ bias } \\
\cline { 2 - 5 } Surface pressure and temperature & GOSAT & OCO-2 & CarbonSat & S-5 P \\
\hline$\Delta P_{\text {surf }}=2 \mathrm{mb}$ & & & & \\
AOD & -0.099 & -0.069 & -0.106 & -0.106 \\
Height & 0.195 & 0.070 & 0.246 & 0.270 \\
\hline$\Delta T_{0-1 \mathrm{~km}}=1 \mathrm{~K}$ & & & & \\
AOD & -0.002 & -0.001 & -0.002 & -0.020 \\
Height & 0.003 & 0.002 & 0.005 & 0.074 \\
\hline Aerosol mixture & GOSAT & OCO-2 & CarbonSat & S-5 P \\
\hline AOD & & & & \\
Max bias (5a) & -0.132 & -0.134 & -0.130 & -0.086 \\
Min (4c) & -0.029 & -0.030 & -0.027 & -0.017 \\
Mean & -0.091 & -0.092 & -0.088 & -0.054 \\
\hline Height & & & & \\
Max bias (5b) & 0.363 & 0.374 & 0.356 & 0.087 \\
Min (4c) & 0.028 & 0.030 & 0.020 & 0.001 \\
Mean & 0.145 & 0.154 & 0.133 & -0.022 \\
\hline
\end{tabular}

the retrieval for each of the other 12 aerosol mixtures from Kahn et al. (2001).

These 12 mixtures typically represent smaller particles with Angstrom coefficients as high as 1.16 for the continental carbonaceous and black-carbon mixture (mixture 5a). The single scattering albedos range from 0.856 for the carbonaceous and continental black-carbon mixture (mixture $5 \mathrm{~b}$ ) to 0.978 for the carbonaceous and dusty maritime mixture (mixture 1a).

The results are shown in the bottom half of Table 4. The biases observed for the AOD retrieval are all negative, which means that the AOD has been underestimated when using a mixture different to mixture $2 \mathrm{~b}$ used in the simulation. AOD biases found for OCO-2, GOSAT and CarbonSat are very similar; the largest biases of up to $\sim 45 \%$ are found for mixtures with the largest Angstrom coefficient, reflecting smaller particles (carbonaceous and black-carbon continental mixtures, mixtures $5 \mathrm{a}-5 \mathrm{c}$; carbonaceous and dusty continental, mixture 4a; carbonaceous and black-carbon maritime, mixtures $4 \mathrm{a}-4 \mathrm{~b}$; carbonaceous and dusty maritime, mixture $1 \mathrm{a}$ ). AOD biases observed for S-5 P are smaller at less than $30 \%$ but with the same trend regarding the Angstrom coefficient.

For the high-resolution instruments OCO-2, GOSAT and CarbonSat we find an overestimation of the aerosol layer height of a few hundred metres with a tendency for mixtures with small particles to result in larger biases. However, the trend with Angstrom coefficient (or particles size) is much weaker compared to the AOD biases, and we find the largest biases for aerosol mixtures with the lowest value of the scattering phase function in the direction of the scattering angle (carbonaceous and black-carbon maritime, mixture 3a) or the lowest value of the single scattering albedo (carbonaceous and black-carbon continental, mixture 5b). Again the biases for height are significantly smaller for S-5 P compared to the instruments with high resolution and biases not exceeding $100 \mathrm{~m}$

\section{Summary and conclusion}

We have assessed the ability of space-based instruments to infer information on the aerosol vertical profile from the $\mathrm{O}_{2}$ A-band with a series of retrieval simulations for the existing GOSAT mission, the upcoming OCO-2 and S-5 P missions and the proposed CarbonSat mission.

From the aerosol profile retrieval simulations for a range of different instrument spectral resolutions and signal-to-noise ratios, we find that high instrument resolution does not necessarily lead to lower errors in the total AOD. In fact, for small AOD errors low resolution combined with high SNR can be preferable, in agreement with Hollstein and Fischer (2014). This low AOD error will, however, come at the expense of vertical information. This behaviour is confirmed by simulations for OCO-2 and S-5 P, which represent these two differing regimes.

Retrieving boundary-layer aerosols with sufficiently small errors of around $0.05-0.1$ and vertical resolutions of $1-2 \mathrm{~km}$ appears difficult for any of the studied four instruments, with the best results often obtained from S-5 P. The retrieval errors for aerosols in the free troposphere are sufficiently smaller, 
and higher spectral resolution instruments such as OCO-2 allow far better retrievals compared to lower-resolution instruments. Though in all cases the surface albedo is a significant cause of low-altitude AOD error through increasing correlations, the resolution of the instruments plays a substantial role through the saturation of Jacobians and thus weaker sensitivity to low-altitude aerosols for higher resolutions.

One major difficulty is the separation of reflection from the surface and scattering by aerosols near the surface which results in the high retrieval errors for AOD in the boundary layer. Imposing a stricter a priori constraint on the surface albedo will help to improve the retrieval precision but we find that the required a priori uncertainty on surface albedo needs to be very low to have a significant impact on the aerosol retrieval and can be as small as $2 \%$ for some scenarios, which is not feasible. Still, making use of a priori knowledge of surface albedo can result in improvements of the aerosol retrieval, especially for low-albedo and/or high-SZA scenarios where the required level of uncertainty on surface albedo is higher.

Since the vertical resolution of the aerosol profile retrieval is low, a suitable (and more robust) alternative to the profile retrieval will be to retrieve only the height and optical depth of an aerosol layer with a pre-defined shape. Although this retrieval does not result in a more precise AOD retrieval if the aerosol is in the boundary layer, it allows very precise retrievals of AOD and height for elevated aerosol layers. Retrieving only a single aerosol layer if there are multiple layers or if the aerosol has a substantially different shape will result in misleading and erroneous retrievals with the result strongly dependent on the vertical sensitivity of the instrument. Retrieving simultaneously two aerosol layers or different shapes can help to mitigate this effect but this has not been further investigated in this study.

Typical assumptions for the aerosol retrieval from the $\mathrm{O}_{2}$ A-band are that surface pressure and aerosol mixture are known. Both assumptions can introduce very significant additional errors of up to $30-40 \%$ in the aerosol retrieval. Surface pressure could be retrieved jointly with aerosols but this would increase the random retrieval error. Some mitigation of the errors from aerosol mixture should be possible by either using information from co-located dedicated aerosol sensors (e.g. A-train instrument for OCO-2) or by using aerosol models. The effect of low-altitude temperature bias was also investigated, resulting in errors of less than $8 \%$; this could be further minimised through a combination with meteorological data.

We find that the use of current or upcoming $\mathrm{O}_{2}$ A-band satellite sensors to monitor boundary-layer aerosols will be limited but, nevertheless, observations from these instruments could provide a powerful way of observing and, in the case of S-5 P or CarbonSat, mapping uplifted plumes of aerosols from forest fires, dust storms or volcanic plumes.

For the analysis of "real" space-based observations, imperfect knowledge of spectroscopy or uncertainties in the in- strument calibration can lead to poorer results as presented in this study. The need for good calibration and improvements to the spectroscopy of the $\mathrm{O}_{2} \mathrm{~A}$-band is widely recognized (Long and Hodges, 2012) and efforts are under way to obtain improved spectroscopic data.

Acknowledgements. This work was funded by the UK Centre of Earth Observation Instrumentation (CEOI). Special thanks to J. Landgraf (SRON) and C. O'Dell (CSU) for help regarding Sentinel-5 $\mathrm{P}$ and OCO-2 respectively as well as the ESA CarbonSat Earth Explorer 8 Candidate Mission "Level-2 and Level-1B Requirements Consolidation Stud". In addition the authors would like to thank colleagues at the University of Leicester, Earth Observation Science Group.

Edited by: P. K. Bhartia

\section{References}

Aben, I., Hasekamp, O., and Hartmann, W.: Uncertainties in the spacebased measurements of $\mathrm{CO}_{2}$ columns due to scattering in the Earth's atmosphere, J. Quant. Spectrosc. Ra., 104, 450-459, 2007.

Bösch, H., Toon, G. C., Sen, B., Washenfelder, R. A., Wennberg, P. O., Buchwitz, M., de Beek, R., Burrows, J. P., Crisp, D., Christi, M., Connor, B. J., Natraj, V., and Yung, Y. L.: Space-based nearinfrared $\mathrm{CO}_{2}$ measurements: Testing the Orbiting Carbon Observatory retrieval algorithm and validation concept using SCIAMACHY observations over Park Falls, Wisconsin, J. Geophys. Res., 111, D23302, doi:10.1029/2006JD007080, 2006.

Boesche, E., Stammes, P., Preusker, R., Bennartz, R., Knap, W. H., and Fischer, J.: Polarization of skylight in the $\mathrm{O}_{2}$ A-band: Effects of aerosol properties, Appl. Optics, 47, 3467-3480, 2008.

Bösch, H., Baker, D., Connor, B., Crisp, D., and Miller, C.: Global Characterization of $\mathrm{CO}_{2}$ Column Retrievals from Shortwave-Infrared Satellite Observations of the Orbiting Carbon Observatory-2 Mission, Remote Sensing, 3, 270-304, 2011.

Bovensmann, H., Burrows, J. P., Buchwitz, M., Frerick, J., Noel, S., Rozanov, V. V., Chance, K. V., and Goede, A. P. H.: SCIAMACHY: Mission Objectives and Measurement Modes, J. Atmos. Sci., 56, 127-150, 1999.

Buchwitz, M., Reuter, M., Bovensmann, H., Pillai, D., Heymann, J., Schneising, O., Rozanov, V., Krings, T., Burrows, J. P., Boesch, H., Gerbig, C., Meijer, Y., and Löscher, A.: Carbon Monitoring Satellite (CarbonSat): assessment of atmospheric $\mathrm{CO}_{2}$ and $\mathrm{CH}_{4}$ retrieval errors by error parameterization, Atmos. Meas. Tech., 6, 3477-3500, doi:10.5194/amt-6-3477-2013, 2013.

Buscaglione, F. and Maresi, L.: GMES Sentinel-5 Precursor - S5P System Requirement Document (SRD), Issue 4, ESA ESTEC, 2011.

Cogan, A. J., Boesch, H., Parker, R. J., Feng, L., Palmer, P. I., Balvier, J.-F. L., Deutscher, N. M., Macatangay, R., Notholt, J., Roehl, C., Warneke, T., and Wunch, D.: Atmospheric carbon dioxide retrieved from the Greenhouse gases Observing SATellite (GOSAT): Comparison with ground-based TCCON observations and GEOS-Chem model calculations, J. Geophys. Res., 117, D21301, doi:10.1029/2012JD018087, 2012. 
Connor, B. J., Bösch, H., Toon, G., Sen, B., Miller, C., and Crisp, D.: Orbiting Carbon Observatory: Inverse method and prospective error analysis, J. Geophys. Res., 113, D05305, doi:10.1029/2006JD008336, 2008.

Corradini, S. and Cervino, M.: Aerosol extinction coefficient profile retrieval in the oxygen A-band considering multiple scattering atmosphere. Test case: SCIAMACHY nadir simulated measurements, J. Quant. Spectrosc. Ra., 97, 354-380, 2006.

Crisp, D., Atlas, R. M., Breon, F.-M., Brown, L. R., Burrows, J. P., Ciais, P., Connor, B. J., Doney, S. C., Fung, I. Y., Jacob, D. J., Miller, C. E., O’Brien, D., Pawson, S., Randerson, J. T., Rayner, P., Salawitch, R. S., Sander, S. P., Sen, B., Stephens, G. L., Tans, P. P., Toon, G. C., Wennberg, P. O., Wofsy, S. C., Yung, Y. L., Kuang, Z., Chudasama, B., Sprague, G., Weiss, P., Pollock, R., Kenyon, D., and Schroll, S.: The Orbiting Carbon Observatory (OCO) mission, Adv. Space Res., 34, 700-709, 2004.

Crisp, D., Miller, C. E., and DeCola, P. L.: NASA Orbiting Carbon Observatory: Measuring the column averaged carbon dioxide mole fraction from space, J. Appl. Remote Sens., 2, p. 23508, 2008.

Crisp, D., Fisher, B. M., O’Dell, C., Frankenberg, C., Basilio, R., Bösch, H., Brown, L. R., Castano, R., Connor, B., Deutscher, N. M., Eldering, A., Griffith, D., Gunson, M., Kuze, A., Mandrake, L., McDuffie, J., Messerschmidt, J., Miller, C. E., Morino, I., Natraj, V., Notholt, J., O’Brien, D. M., Oyafuso, F., Polonsky, I., Robinson, J., Salawitch, R., Sherlock, V., Smyth, M., Suto, H., Taylor, T. E., Thompson, D. R., Wennberg, P. O., Wunch, D., and Yung, Y. L.: The ACOS $\mathrm{CO}_{2}$ retrieval algorithm - Part II: Global $X_{\mathrm{CO}_{2}}$ data characterization, Atmos. Meas. Tech., 5, 687707, doi:10.5194/amt-5-687-2012, 2012.

Dubuisson, P., Frouin, R., Dessailly, D., Duforêt, L., Léon, J. F., Voss, K., and Antoine, D.: Estimating the altitude of aerosol plumes over the ocean from reflectance ratio measurements in the $\mathrm{O}_{2}$ A-band, Remote Sens. Environ., 113, 1899-1911, 2009.

Dufresne, J.-L., Gautier, C., Ricchhiazzi, P., and Fouquart, Y.: Longwave Scattering Effects of Mineral Aerosols, J. Atmos. Sci., 59, 1959-1966, 2002.

Fischer, H., Birk, M., Blom, C., Carli, B., Carlotti, M., von Clarmann, T., Delbouille, L., Dudhia, A., Ehhalt, D., Endemann, M., Flaud, J. M., Gessner, R., Kleinert, A., Koopman, R., Langen, J., López-Puertas, M., Mosner, P., Nett, H., Oelhaf, H., Perron, G., Remedios, J., Ridolfi, M., Stiller, G., and Zander, R.: MIPAS: an instrument for atmospheric and climate research, Atmos. Chem. Phys., 8, 2151-2188, doi:10.5194/acp-8-2151-2008, 2008.

Frankenberg, C., Hasekamp, O., O’Dell, C., Sanghavi, S., Butz, A., and Worden, J.: Aerosol information content analysis of multiangle high spectral resolution measurements and its benefit for high accuracy greenhouse gas retrievals, Atmos. Meas. Tech., 5, 1809-1821, doi:10.5194/amt-5-1809-2012, 2012.

Frankenberg, C., Butz, A., and Toon, G. C.: Disentangling chlorophyll fluorescence from atmospheric scattering effects in $\mathrm{O}_{2}$ Aband spectra of reflected sun-light, Geophys. Res. Lett., 755, L03801, doi:10.1029/2010GL045896, 2011.

Gordon, H. R., Du, T., and Zhang, T.: Remote sensing ocean color and aerosol properties: resolving the issue of aerosol absorption, Appl. Optics, 36, 8670-8684, 1997.

Hanel, R. A.: Determination of cloud altitude from a satellite, J. Geophys. Res., 66, p. 1300, 1961.
Heidinger, A. K. and Stephens, G. L.: Molecular Line Absorption in a Scattering Atmosphere. Part II: Application to Remote Sensing in the $\mathrm{O}_{2}$ A band, J. Atmos. Sci., 57, 1615-1634, 2000.

Hollstein, A. and Fischer, J.: Retrieving aerosol height from the oxygen A band: a fast forward operator and sensitivity study concerning spectral resolution, instrumental noise, and surface inhomogeneity, Atmos. Meas. Tech., 7, 1429-1441, doi:10.5194/amt7-1429-2014, 2014.

Hunt, W. H., Winker, D. M., Vaughan, M. A., Powell, K. A., Lucker, P. L., and Weimer, C.: CALIPSO Lidar Description and Performance Assessment, J. Atmos. Ocean. Tech., 26, 1214-1228, 2009.

Ingmann, P., Veihelmann, B., Langen, J., Lamarre, D., Stark, H., and Courreges-Lacoste, G. B.: Requirements for the GMES Atmosphere Service and ESA's implementation concept: Sentinels4/-5 and-5p, Remote Sens. Environ., 120, 58-69, 2012.

IPCC: Climate change 2013: the physical science basis. Contribution of working group I to the fifth assessment report of the intergovernmental panel on climate change, Cambridge University Press, 2013.

Kahn, R., Banerjee, P., and McDonald, D.: Sensitivity of multiangle imaging to natural mixtures of aerosols over ocean J. Geophys. Res, 106, 18219-18238, 2001.

Kahn, R. A., Li, W. H., Moroney, C., Diner, D. J., Martonchik, J. V., and Fishbein, E.: Aerosol source plume physical characteristics from space-based multiangle imaging, J. Geophys. Res.-Atmos., 112, D11205, doi:10.1029/2006JD007647, 2007.

Kaufman, Y. J., Tanré, D., and Boucher, O.: A satellite view of aerosols in the climate system, Nature, 419, 215-223, 2002.

Kuze, A., Suto, H., Nakajima, M., and Hamazaki, T.: Thermal and near infrared sensor for carbon observation Fourier-transform spectrometer on the Greenhouse Gases Observing Satellite for greenhouse gases monitoring, Appl. Optics, 48, 6716-6733, 2009.

Long, D. A. and Hodges, J. T.: On spectroscopic models of the $\mathrm{O}_{2}$ A-band and their impact upon atmospheric retrievals, J. Geophys. Res., 117, D12309, doi:10.1029/2012JD017807, 2012.

Llewellyn, E. J., Lloyd, N. D., Degenstein, D. A., Gattinger, R. L., Petelina, S. V., Bourassa, A. E., and Sjoberg, F.: The OSIRIS instrument on the Odin spacecraft, Can. J. Phys., 82, 411-422, 2004.

Mauldin III, L. E., Zaun, N. H., McCormick Jr., M. P., Guy, J. H., and Vaughn, W. R.: Stratospheric Aerosol and Gas Experiment II instrument: A functional description, Optical Eng., 24, 242307 242307, 1985.

Natraj, V. and Spurr, R. J. D.: A Fast Linearized Pseudo-Spherical Two Orders of Scattering Model to Account for Polarization in Vertically Inhomogeneous Scattering-Absorbing Media, J. Quant. Spectrosc. Ra., 107, 263-293, 2007.

O'Brien, D. M. and Mitchell, R. M.: Error Estimates for Retrieval of Cloud-Top Pressure Using Absorption in the A Band of Oxygen, J. Appl. Meteorol., 31, 1179-1192, 1992.

O'Dell, C. W.: Acceleration of multiple-scattering, hyperspectral radiative transfer calculations via low-streams interpolation, J Geophys. Res., 115, D10206, doi:10.1029/2009JD012803, 2010.

Parker, R., Bösch, H. Cogan, A., Fraser, A., Feng, L., Palmer, P., Messerschmidt, J., Deutscher, N. Griffith, D., Notholt, J., Wennberg, P., and Wunch, W.: Methane observations from the Greenhouse Gases Observing SATellite: Comparison to ground- 
based TCCON data and model calculations, Geophys. Res. Lett., 38, L15807, doi:10.1029/2011GL047871, 2011.

Purser, R. J. and Huang, H.-L.: Estimating Effective Data Density in a Satellite Retrieval or an Objective Analysis, J. Appl. Meteorol., 32, 1092-1107, 1993.

Rodgers, C. D.: Inverse Methods for Atmospheric Sounding: Theory and Practice, World Scientific, Singapore, 2000.

Russell, J. M., Gordley, L. L., Park, J. H., Drayson, S. R., Hesketh, W. D., Cicerone, R. J., Tuck, A. F., Frederick, J. E., Harries, J. E., and Crutzen, P. J.: The halogen occultation experiment, J. Geophys. Res.-Atmos., 98, 10777-10797, 1993.

Sanders, A. F. J. and de Haan, J. F.: Retrieval of aerosol parameters from the oxygen A band in the presence of chlorophyll fluorescence, Atmos. Meas. Tech., 6, 2725-2740, doi:10.5194/amt-62725-2013, 2013.

Satheesh, S. K., Torres, O., Remer, L. A., Suresh Babu, S., Vinoj, V., Eck, T. F., Kleidman, R. G., and Holben, B. N.: Improved assessment of aerosol absorption using OMIMODIS joint retrieval, J. Geophys. Res.-Atmos., 114, D05209, doi:10.1029/2008JD011024, 2009.

Siddans, R., Latter, B. G., and Kerridge, B. J.: Study to Consolidate the UVS Mission Requirements for the Oxygen A-band, Eumetsat Contract No. EUM/CO/05/1411/SAT, 2007.
Spurr, R. J. D., Kurosu, T. P., and Chance, K. V.: A Linearized Discrete Ordinate Radiative Transfer Model for Atmospheric Remote Sensing Retrieval, J. Quant. Spectrosc. Ra., 68, 689-735, 2001.

Val Martin, M., Logan, J. A., Kahn, R. A., Leung, F.-Y., Nelson, D. L., and Diner, D. J.: Smoke injection heights from fires in North America: analysis of 5 years of satellite observations, Atmos. Chem. Phys., 10, 1491-1510, doi:10.5194/acp-10-14912010, 2010.

WHO (World Health Organisation): Department of Public Health and Environment, Estimated Deaths and DALYs attributable to selected environmental risk factors, by WHO member states 2002, 2007.

WMO: Report of the WMO workshop on the measurement of atmospheric optical depth and turbidity, edited by: Hicks, B., WMO/TD-No 659/GAW publication No. 101, 1994.

Yamamoto, G. and Wark, D. Q.: Discussion of the letter by R. A. Hanel, "Determination of cloud altitude from a satellite", J. Geophys. Res., 66, 3596-3596, doi:10.1029/JZ066i010p03596, 1961. 